\title{
Selection and characterization of promoters based on genomic approach for the molecular breeding of oleaginous fungus Mortierella alpina 1S-4.
}

\section{$\operatorname{AUTHOR}(\mathrm{S})$ :}

Okuda, Tomoyo; Ando, Akinori; Sakuradani, Eiji; Kikukawa, Hiroshi; Kamada, Nozomu; Ochiai, Misa; Shima, Jun; Ogawa, Jun

\section{CITATION:}

Okuda, Tomoyo ...[et al]. Selection and characterization of promoters based on genomic approach for the molecular breeding of oleaginous fungus Mortierella alpina 1S-4..

Current genetics 2014, 60(3): 183-191

\section{ISSUE DATE:}

2014-02-22

URL:

http://hdl.handle.net/2433/198766

\section{RIGHT:}

The final publication is available at Springer via http://dx.doi.org/10.1007/s00294-0140423-4.; This is not the published version. Please cite only the published version.; この論 文は出版社版でありません。引用の際には出版社版をご確認ご利用ください。 


\title{
Selection and characterization of promoters based on genomic approach for the molecular breeding of oleaginous fungus Mortierella alpina 1S-4
}

Tomoyo Okuda $\cdot$ Akinori Ando · Eiji Sakuradani $\cdot$ Hiroshi Kikukawa · Nozomu Kamada $\cdot$ Misa Ochiai $\cdot$ Jun Shima $\cdot$ Jun Ogawa*

Tomoyo Okuda, Akinori Ando, Eiji Sakuradani, Hiroshi Kikukawa and Jun Ogawa Division of Applied Life Sciences, Graduate School of Agriculture, Kyoto University, Kitashirakawa-oiwakecho, Sakyo-ku, Kyoto 606-8052, Japan

\author{
Akinori Ando \\ Research Unit for Physiological Chemistry, Kyoto University, \\ Kitashirakawa-oiwakecho, Sakyo-ku, Kyoto 606-8052, Japan
}

Nozomu Kamada and Misa Ochiai

Research Institute, Suntory global Innovation Center Ltd.,

1-1-1 Wakayamadai, Shimamoto-cho, Mishima-gun, Osaka 618-8503, Japan

Jun Shima

Research Division of Microbial Sciences Kyoto University,

Kitashirakawa-oiwakecho, Sakyo-ku, Kyoto 606-8052, Japan

Corresponding author: Jun Ogawa

Tel: +81757536113

Fax: +81757536128

E-mail: ogawa@kais.kyoto-u.ac.jp 


\section{Abstract}

To express a foreign gene effectively, a good expression system is required. In this study, we investigated various promoters as useful tools for gene manipulation in oleaginous fungus Mortierella alpina 1S-4. We selected and cloned the promoter regions of 28 genes in $M$. alpina $1 \mathrm{~S}-4$ on the basis of expression sequence tag (EST) abundance data. The activity of each promoter was evaluated by using the $\beta$-glucuronidase (GUS) reporter gene. Eight of these promoters were shown to enhance GUS expression more efficiently than a histone promoter, which is conventionally used for the gene manipulation in M. alpina. Especially, the predicted protein $3(P P 3)$ and the predicted protein $6(P P 6)$ promoters demonstrated approximately 5-fold higher activity than the histone promoter. The activity of some promoters changed along with the cultivation phase of $M$. alpina 1S-4. Seven promoters with constitutive or time-dependent, high-level expression activity were selected, and deletion analysis was carried out to determine the promoter regions required to retain activity. This is the first report of comprehensive promoter analysis based on a genomic approach for M. alpina. The promoters described here will be useful tools for gene manipulation in this strain.

Key Words: Mortierella alpina, promoter, Expression sequence tag, gene manipulation 


\section{Introduction}

The properties of promoters strongly influence the expression level and duration of target genes (Jefferson, et al. 1987, Mumberg, et al. 1994, Wurm 2004). The application of highly expressing and/or regulated promoters is one of most important factors in a valuable expression system. Many investigations for useful promoters have been carried out and contributed to the improvement of heterologous protein production in various microorganisms. In Escherichia coli, for example, the bacteriophage T7 promoter system has been used to accumulate recombinant proteins at high concentrations (40-50\%) of total cell protein (Baneyx 1999). In the methylotrophic yeast Pichia pastoris, strong methanol-inducible promoters have been used to produce various medically important proteins have been produced (Cereghino and Cregg 2000, Hansson, et al. 1993, Sumi, et al. 1999). Also in fungi, mainly in Aspergillus species, the investigation and modification of high-expression promoters has led to successful high-level production of heterologous proteins such as glucoamylase, protease, and lipase (Archer, et al. 1994, Ichishima, et al. 1999, MacKenzie, et al. 1993, Punt, et al. 2002).

Recently, functional lipids such as polyunsaturated fatty acids (PUFAs) have been recognized for their beneficial effects on human health (Gill and Valivety 1997). In 
addition, lipid fermentation by microorganisms with high fatty acid selectivity is expected to serve as an alternative method supplying PUFA more stably than conventional production from plant-seed oils and fish oils (Ratledge 1993). Therefore, the development of gene manipulation tools for lipid-producing microorganisms is important. In fact, various lipids have been produced by means of molecular breeding of microorganisms in some studies (Beopoulos, et al. 2011, Courchesne, et al. 2009, Raghukumar 2008, Sakuradani, et al. 2013). Mortierella alpina 1S-4, an oleaginous fungus, is a lipid-producing microbe (Shimizu, et al. 1997). To date, the production of various kinds of PUFAs, such as arachidonic acid, dihomo- $\gamma$-linolenic acid, Mead acid and eicosapentaenoic acid has been achieved by molecular breeding of M. alpina (Jareonkitmongkol, et al. 1992, Jareonkitmongkol, et al. 1993, Kawashima, et al. 1997, Sakuradani, et al. 2013). Basic molecular breeding tools such as gene delivery systems, host-vector systems and transformation systems using auxotrophy or antibiotic resistance have been established in M. alpina 1S-4 (Ando, et al. 2009a, Takeno, et al. 2004a, Takeno, et al. 2005). However, the gene modifiability of M. alpina is still limited due to lack of identification of variations in promoters (Mackenzie, et al. 2000). For further development of gene expression systems, such as multiple gene expression, temporally regulated expression and inducible expression, it is necessary to prepare 
various kinds of promoters. Enrichment of promoter types would contribute to improving PUFA productivity and modifying PUFA composition, and may help elucidate the mechanisms regulating gene expression in M. alpina.

In general, promoter discovery in fungal biotechnology has been mainly based on the information of highly- or constitutively-expressed proteins (Hata, et al. 1991, Tada, et al. 1991). Recently, expression sequence tag (EST) analysis has been used as a powerful tool for investigating expressed genes. EST abundance data can present directly gene transcriptional levels, and make possible widespread approaches to find desired promoters in combination with the genomic information (Kusakabe, et al. 1994, Ranamalie Amarasinghe, et al. 2006).

In this study, we selected and cloned promoter regions of various genes of M. alpina $1 \mathrm{~S}-4$ on the basis of EST abundance data, and characterized these promoter regions by fusing $\beta$-glucuronidase (GUS) reporter assays. 


\section{Materials and Methods}

Strains, media, and growth conditions

A uracil auxotroph ( $\mathrm{ura}^{-}$strain), previously isolated from M. alpina $1 \mathrm{~S}-4$ deposited at the Graduate School of Agriculture of Kyoto University (Takeno, et al. 2004b), was used as a recipient host strain for transformation. Czapek-Dox agar medium, supplemented with $0.05 \mathrm{mg} / \mathrm{ml}$ uracil, was used for sporulation of the $u r a 5^{-}$strain, as described previously (Takeno, et al. 2004b). SC agar medium (Takeno, et al. 2004b) was used as a uracil-free synthetic medium for cultivation of the transformants derived from M. alpina $1 \mathrm{~S}-4 \mathrm{ura}^{-}$strain at $28^{\circ} \mathrm{C}$. GY medium $(2 \%$ [wt/vol] glucose and $1 \%$ yeast extract) was used for reporter assays and extracting genomic DNA. GS medium (5\% [wt/wt] soy flour, $0.3 \% \mathrm{~K}_{2} \mathrm{HPO}_{4}, 0.05 \% \mathrm{MgCl}_{2} \cdot 6 \mathrm{H}_{2} \mathrm{O}$ and $\left.0.05 \% \mathrm{CaCl}_{2} \cdot 2 \mathrm{H}_{2} \mathrm{O}\right)$ was used for large-scale cultivation. Liquid cultivations were performed at $28^{\circ} \mathrm{C}$ with shaking (300 rpm), except for large-scale cultivation when a jar-fermentor was used.

Escherichia coli strain DH5 $\alpha$ was used for DNA manipulation and grown on LB agar plates containing $50 \mu \mathrm{g} / \mathrm{ml}$ kanamycin.

Agrobacterium tumefaciens C58C1 was used for the transformation of M. alpina 1S-4 ura $^{-}$strain. LB-Mg agar medium, minimal medium (MM) and induction medium (IM) 
were used for the transformation, cultivation and infection of A. tumefaciens, respectively. The compositions of LB-Mg agar medium, MM, and IM have been described previously (Takeno, et al. 2004b).

\section{Genomic DNA preparation}

M. alpina $1 \mathrm{~S}-4$ was cultivated in $10 \mathrm{ml}$ of $\mathrm{GY}$ medium at $28^{\circ} \mathrm{C}$ for $4 \mathrm{~d}$ with shaking (300 rpm). Fungal mycelia were harvested by suction filtration and washed twice with sterile water. Preparation of genomic DNA was performed using a method described previously (Sakuradani, et al. 1999).

\section{Construction of cDNA libraries of M. alpina $1 S-4$ and EST analysis}

For large-scale cultivation, an inoculum was prepared in a 50-L jar fermentor containing 30 L of GY medium supplemented with $0.1 \%$ soybean oil, followed by cultivation for $2 \mathrm{~d}$ at $28^{\circ} \mathrm{C}$. The main cultivation was carried out in a $10-\mathrm{kL}$ fermentor (Kansai Chemical Engineering Co., Hyogo, Japan) with $4 \mathrm{~kL}$ of GS medium at $26^{\circ} \mathrm{C}$ with stirring. At $18,42,66,90$ and $114 \mathrm{~h}$ after starting cultivation, $5.33 \%$ or $4 \%$ glucose was added. For extracting the total RNA of M. alpina, fungal mycelia were sampled after 17, 25, 42, 114, 209 and $281 \mathrm{~h}$ of cultivation. Total RNA was extracted from each 
sample by using RNeasy Mini Kit (QIAGEN).

First strand cDNA was synthesized by using SOLiD $^{\mathrm{TM}}$ Total RNA-Seq for Whole Transcriptome Libraries (Applied Biosystems, Inc., California, USA). For EST and transcriptome analysis, we used a research contract service (Genaris, Inc., Kanagawa, Japan).

Cloning of $\mathrm{M}$. alpina promoters

Information regarding selected promoters analyzed in this study is shown in Table 1. Selected promoter regions were cloned from the genome of M. alpina $1 \mathrm{~S}-4$ by PCR performed using specific primers (Table S1) designed on the basis of the information available in the genomic database for this strain. Putative PolII transcriptions sites in these promoter sequences were predicted by using Promoter 2.0 Prediction Server (http://www.cbs.dtu.dk/services/Promoter/). For deletion constructs, the anti-sense primers used for PCR are shown in Table S1 and forward primers are shown in Table S2. $X b a \mathrm{I}$ and SpeI restriction enzyme sites were created at the $5^{\prime}$ end of each forward primer and at the $3^{\prime}$ end of each reverse primer, respectively. When an $X b a \mathrm{I}$ site was present in the promoter region, an SpeI site was created instead of the $X b a \mathrm{I}$ site at the $5^{\prime}$ end of the forward primer. When an SpeI site was present in the promoter region, an $\mathrm{XbaI}$ site was 
created instead of the SpeI site at the 3' end of the reverse primer.

Construction of GUS reporter gene-carrying vectors for promoter analysis

The reporter gene vectors were constructed on the backbone of pBIG3ura5s (Ando, et al. 2009b). The histone promoter (the histone H4.1 promoter short fragment (Ando, et al. 2009b)), succinate dehydrogenase subunit B (SdhB) terminator (Ando, et al. 2009a) and the ura5 marker gene (Takeno, et al. 2004a) were amplified from the genomic DNA of M. alpina 1S-4. The ura5 expression cassette controlled by a histone promoter and $S d h B$ terminator was generated by fusion PCR with additional EcoRI and $X b a \mathrm{I}$ restriction enzyme sites at the $5^{\prime}$ and $3^{\prime}$ ends, respectively, of this cassette. The ura5 expression cassette, digested with EcoRI and $X b a \mathrm{I}$, was ligated to pBIG3ura5s (Ando, et al. 2009b) digested with the same restriction enzymes and designated as pBIG35Zh.

The $\beta$-Glucuronidase (GUS) gene was synthesized with optimized codon usage to reflect the codon bias of $M$. alpina $1 \mathrm{~S}-4$ obtained from the Kazusa database (http://www.kazusa.or.jp/codon/), with additional SpeI and BamHI restriction enzyme sites at the $5^{\prime}$ and $3^{\prime}$ flanking ORFs, respectively. The GUS expression cassette, controlled by a histone promoter and $S d h B$ terminator, was generated by fusion PCR with additional $X b a \mathrm{I}$ and NheI restriction sites at the $5^{\prime}$ and $3^{\prime}$ ends of the cassette, 


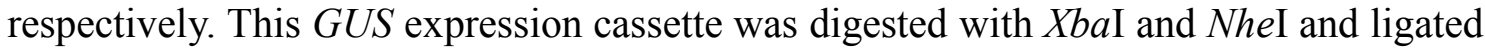
to $\mathrm{pBIG} 35 \mathrm{Zh}$ digested with same restriction enzymes and designated pBIG35ZhGUSm (Fig. 1). In this vector, the histone promoter region, located upstream of the GUS gene, can be removed by digestion with $X b a \mathrm{I}$ and SpeI, and replaced by another promoter fragment digested with $X b a \mathrm{I}$ and/or SpeI for promoter assays.

Transformation of $\mathrm{M}$. alpina $1 S-4$ ura $5^{-}$strain

A spore suspension of $M$. alpina $1 \mathrm{~S}-4 u r a 5^{-}$strain was freshly prepared by harvesting from cultures grown on Czapek-Dox agar medium supplemented with $0.05 \mathrm{mg} / \mathrm{ml}$ uracil and then filtering the suspension through Miracloth (Calbiochem) (Takeno, et al. 2004b).

Transformation of M. alpina $1 \mathrm{~S}-4 \mathrm{ura}^{-}$strain was performed using the Agrobacterium tumefaciens-mediated transformation (ATMT) method described previously (Ando, et al. 2009b) with slight modification. Briefly, Agrobacterium tumefaciens C58C1 was transformed with each vector via electroporation as described previously (Shen and Forde 1989) and its transformants were isolated on LB-Mg agar plates supplemented with kanamycin $(20 \mu \mathrm{g} / \mathrm{ml})$, ampicillin $(50 \mu \mathrm{g} / \mathrm{ml})$ and rifampicin $(50 \mu \mathrm{g} / \mathrm{ml})$. Agrobacterium tumefaciens transformants were cultivated in $100 \mathrm{ml}$ of $\mathrm{MM}$ 
supplemented with kanamycin $(20 \mu \mathrm{g} / \mathrm{ml})$ and ampicillin $(50 \mu \mathrm{g} / \mathrm{ml})$ at $28^{\circ} \mathrm{C}$ for $48 \mathrm{~h}$ with shaking $(120 \mathrm{rpm})$. Bacterial cells were harvested by centrifugation at $8,000 \times g$, washed once with fresh IM, and then diluted to an optical density of $660 \mathrm{~nm}\left(\mathrm{OD}_{660}\right)$ of $0.1-0.2 \mathrm{in} 10 \mathrm{ml}$ of fresh IM. After pre-incubation for $12-16 \mathrm{~h}$ at $28^{\circ} \mathrm{C}$ with shaking (300 rpm) to an $\mathrm{OD}_{660}$ of $1.5-2.0,100 \mu \mathrm{l}$ of the bacterial cell suspension was mixed with an equal volume of a spore suspension $\left(10^{8}\right.$ spores $\left./ \mathrm{ml}\right)$ of $M$. alpina $1 \mathrm{~S}-4 \mathrm{ura5}^{-}$ strain, and then spread on membranes (Whatman \#50 Hardened Circles, $70 \mathrm{~mm}$, Whatman International Ltd. UK) kept on cocultivation media (IM with 1.5\% agar) and incubated at $23^{\circ} \mathrm{C}$ for $5 \mathrm{~d}$. After cocultivation, the membranes were transferred to uracil-free SC agar plates that contained $0.03 \%$ Nile blue A (Sigma-Aldrich Japan) to distinguish between fungal colonies and the white color of the membrane. After $2 \mathrm{~d}$ of incubation at $28^{\circ} \mathrm{C}$, hyphae from visible fungal colonies were transferred to fresh uracil-free SC agar plates, this was repeated 3 times to obtain candidates. Integration of the vector into the chromosome of the host strain was verified by PCR, as described previously (Takeno, et al. 2004b).

Preparation of cell-free extracts for GUS assays

Cell-free extracts of $M$. alpina were prepared by a slight modification of a method 
described previously (Takeno, et al. 2004a). All transformants and the wild-type strain of M. alpina $1 \mathrm{~S}-4$ were cultivated in $10 \mathrm{ml}$ of $\mathrm{GY}$ medium for $2-14 \mathrm{~d}$ at $28^{\circ} \mathrm{C}$ with shaking (300 rpm), harvested by suction filtration, and washed twice with sterile water. Fungal mycelia were suspended in 2 volumes of $100 \mathrm{mM}$ Tris- $\mathrm{HCl}$ containing $5 \mathrm{mM}$ 2-mercaptoethanol ( $\mathrm{pH} 7.5)$ and then disrupted by using a bead shocker (Wakenyaku Co. Ltd., Kyoto, Japan) at 5,000 rpm for $30 \mathrm{~s}$ twice with glass beads ( $\varphi 1.0 \mathrm{~mm}$, Waken B Tech Co. Ltd., Kyoto, Japan). The extract was centrifuged at $15,000 \times g$ for $10 \mathrm{~min}$ to remove cell debris and intact cells. The supernatant was used for the GUS assay as cell-free extract. All steps were performed at $4{ }^{\circ} \mathrm{C}$.

\section{GUS assay and protein measurement}

$\beta$-Glucuronidase (GUS) assays were performed as described previously (Jefferson, et al. 1986). Enzyme activity was calculated in terms of nanomoles of p-nitrophenol production per milligram of protein per minute at $37^{\circ} \mathrm{C}$. Protein concentration was measured according to the Bradford method, using bovine serum albumin as a standard (Bradford 1976).

Nucleotide sequence accession number 
The sequences of selected promoters were deposited in DDBJ, under the following accession numbers; PP1 (AB871464), PP2 (AB859208), PP3 (AB859209), SSA2 (AB859212), $\quad$ PP7 (AB859213), $\quad$ SSA22 (AB871467), PP4 (AB871465), PP8 (AB871479), SAH1 (AB871466), PET9 (AB871478), HSP104 (AB871471), HSC82 (AB859211), UBC5 (AB871477), CDA1 (AB871469), RPP0 (AB871473), PP5 (AB871472), PP6 (AB859210), RPS16B (AB871474), EFB1 (AB871460), TDH1 (AB871475), CIT1 (AB859214.), TIF2 (AB871476), CAT2 (AB871468), ELO1 (AB871470), IPP1 (AB871461), OLE1 (AB871462) and PGK1 promoter (AB871463). 


\section{Results}

Selection, cloning and evaluation of various promoters of $\mathrm{M}$. alpina $1 S-4$

We cultivated $M$. alpina $1 \mathrm{~S}-4$ on GS medium and prepared cDNA libraries by using RNA extracted from the mycelia on different cultivation stages (see Materials and Methods). EST analysis were performed for each cDNA sample, and the abundances of each EST clone during all cultivation stages were summed (data not shown). These totals were sorted in descending order. On the basis of these EST abundance data and previous reports regarding conventional promoters of other organisms (Makrides 1996, Ostergaard, et al. 2000, Twyman, et al. 2003, Wurm 2004), putative promoter regions of 28 genes of $M$. alpina $1 \mathrm{~S}-4$ were selected as candidates of highly-expressing and/or temporally-regulated promoters (Table 1). Considering of the positions of putative transcriptional factor-binding sites in each selected promoter region, we cloned approximately $1000-2500 \mathrm{bp}$ of the 5' flanking region of individual ORFs were cloned as putative promoter regions from the genomic DNA of $M$. alpina $1 \mathrm{~S}-4$. To evaluate the activity of these putative promoters in $M$. alpina, pBIG35ZhGUSm plasmids carrying each putative promoter region, instead of the histone promoter, located upstream of the $\beta$-glucuronidase (GUS) gene were constructed (Fig. 1) and transformed into M. alpina 
1S-4 using the ATMT method. For each construct, 30 transformants were randomly selected and cultivated for $5 \mathrm{~d}$ in GY liquid medium, and then their GUS activities were measured. Due to the variety in GUS activity in individual $M$. alpina transformant lines with each promoter construct (a representative pattern is shown in Fig. 2), we used the average value of GUS activities in the 10 moderately expressing lines for comparison with different promoter activities (Fig. 3). As shown in Fig. 3, PP1, PP3, SSA2, PP7, $H S C 82, P P 6, T D H 1$ and $C I T 1$ promoters led to increased GUS activity compared with a conventional histone promoter. In particular, $P P 3$ and PP6 promoters showed approximately 5 -fold higher activity than the histone promoter.

We also carried out the same experiments with GS medium, which was used for large-scale cultivation (see Materials and Methods). There were no apparent differences in the GUS activity levels between GY and GS media (data not shown). Therefore, GY medium was used to cultivate transformants in all subsequent GUS assays.

Time course measurements of promoter activity during cultivation of $\mathrm{M}$. alpina $1 S-4$

Transformants with each promoter construct were cultivated in GY medium for 2-14 d and then GUS activity was evaluated in order to investigate the effect of cultivation time on GUS activity with different promoters (Fig. 4). Based on the pattern of 
time-dependent changes in GUS activity, promoters could be categorized into the following 4 groups; GUS activity levels controlled by the HSC82, PP7, SSA2, HSP104, UBC5 or PET9 promoter were almost constant throughout the cultivation period (Fig. 4A). With the CIT1, PP8, SAH1, EFB1, OLE1, HSC82, CDA1, RPP0, RPS16B or CAT2 promoter, GUS activity levels were higher in the early stage of cultivation and then decreased (Fig. 4B). GUS activity controlled by the PP6, ELO1 or TDH1 promoter peaked at the middle stage of cultivation (Fig. 4C). With the $P P 3, P P 2, P P 4, P P 5$, SSA22, IPP1 or PGK1 promoter, GUS activity levels were low in the early stage, and then increased with cultivation time (Fig. 4D).

PP2, PP3, PP6, PP7, SSA2, HSC82 and CIT1 promoters with constitutive or time-dependent high-level activity were selected and used for subsequent studies.

\section{Deletion analysis}

In order to investigate the length of the promoter regions required to maintain high expression activity, a series of $5^{\prime}$ deletion constructs of the 7 selected promoters were generated (Fig. 5, left column) and introduced into M. alpina 1S-4. For each deletion construct, 30 randomly selected transformants were cultivated in GY medium for the appropriate number of days based on the above results, and then GUS activity was 
evaluated. For comparison, the GUS activity levels of 10 moderately expressing lines were averaged and represented as a value relative to each full-length promoter, which was set as $100 \%$ (Fig. 5, right column). In the PP2, PP3 and PP6 promoters, relatively long lengths of the promoter regions (over 1,000 bp) were required for high GUS expression, and the GUS activity levels dramatically diminished with deletion of the $5^{\prime}$ regions. In contrast, the other promoters maintained high activity even in relatively short regions (approximately 400-800 bp). 


\section{Discussion}

In general, promoters that are useful for gene manipulation systems exhibit either constitutively high, time-dependent and/or conditionally inducible expression. Thus, we investigated and screened beneficial promoters for M. alpina gene manipulation using an EST-based approach in this view point. EST abundance data can provide gene expression levels without post-translational influence. Therefore, by using an EST-based approach, the desired promoters can be identified more directly and efficiently than by using conventional approaches based on information on protein expression.

In many cases, EST analysis is employed to obtain transcriptional information at a certain point in the cultivation period. Because the transcriptional level of each gene generally changes depending on the cultivation stage, we carried out EST analysis with M. alpina at different cultivation stages. On the basis of the EST data and previous reports on conventional promoters of other organisms, 28 promoters of M. alpina 1S-4 were selected as candidates for highly expressing and/or regulated promoters (see Table $1)$.

The GUS reporter gene was used to monitor the promoter activity in this study because the GUS gene has been commonly used as a reporter gene for promoter assays for various organisms (Jefferson, et al. 1987, Tada, et al. 1991). In addition, we considered 
that this study also means investigation of heterologous gene expression in M. alpina, because the GUS gene is a heterologous gene for this strain.

The GUS activity in M. alpina transformant lines with each promoter construct was distributed across a wide range (Fig. 2). This dispersion might be attributable to the differing locations of the GUS gene in chromosomal DNA, i.e., the position effect. It has previously been reported that $M$. alpina transformants generated by the ATMT method have a single copy of T-DNA at a random location in chromosomal DNA (Ando, et al. 2009b).

Our comprehensive analysis showed that the PP3 and PP6 promoters were demonstrate remarkably higher GUS activity than the conventional histone promoter in M. alpina. The functions of the proteins coded by the PP3 and PP6 genes are unknown. Investigation of the function of these proteins functions might lead to new findings, which may in turn lead to new insights on M. alpina physiology. Interestingly, the GUS expression levels were not necessarily proportional to the EST abundance values (compare Fig. 3 with Table 1). There were some cases where the GUS expression levels were much lower than expected from the EST abundance data, e.g. the SSA22 and PP8 promoters. In such cases, other factors besides promoters, such as the terminator and post-transcriptional processing might lead to high-transcriptional levels of the original 
gene, unlike the findings seen for heterologous GUS gene expression.

Time-course measurements of GUS activity levels with various promoters showed several temporally-different patterns of expression (Fig. 4). Also in this examination, the GUS expression patterns were not necessarily consistent to the time course of EST abundance values (data not shown). It might be caused by difference of cultivation conditions. Especially, we performed glucose feeding on industrial cultivation for EST analysis (see Materials and Methods). Glucose starvation might be one of most important factors for cultivation phase-specific expression.

To our knowledge, this is the first report of time-dependent expression promoters in $M$. alpina. These promoters allow for phase-specific expression in M. alpina, unlike the conventional histone promoter expressing constitutively during cultivation time (data not shown). These time-dependent promoters could contribute to more efficient production of PUFAs in M. alpina by means of temporal coordination of enzyme expression with PUFA biosynthesis.

For the $5^{\prime}$ deletion analysis of promoter regions, 7 promoters were selected because of their characteristic expression patterns, such as high-level expression and/or time-dependent expression. A relatively long length (over 1,000 bp) was required to maintain high activity in the $P P 2, P P 3$ and $P P 6$ promoters. This finding is agreement 
with the prediction of putative transcription factor binding sites of these promoters (Fig.

5). In contrast, the $S S A 2, P P 7, H S C 82$ and $C I T 1$ promoters retained sufficient activity even in the truncated form (400-800 bp). These short promoters with high activity will be advantageous in applications involving $M$. alpina gene manipulation because they will be useful for convenient vector construction.

In some promoters, SSA2p and HSC82p, the length of promoter region with high activity were not correlated with the position of putative transcription factor binding sites (Fig. 5). Practically the reliable prediction for such sites is difficult in zygomycetes including $M$. alpina because the investigation of their transcriptional regulatory mechanism is still underdeveloped. More detailed deletion analysis and consensus sequence analysis of highly-expressing and/or regulated promoters will help identify functionally essential elements for transcriptional regulation. This in turn could help elucidate the transcriptional regulatory mechanisms of $M$. alpina. The information of transcriptional regulatory elements of promoters for high-level expression and time-dependent expression is also useful for applications. For example, in Aspergillus oryzae, the introduction of multiple copies of the consensus sequence found in the high-expression promoters has been reported to improve promoter activity (Minetoki, et al. 1998). We could not find such consensus sequences inherent in each expression 
property of promoters identified in this study (data not shown), therefore more detailed investigations are required.

In conclusion, we found several potent promoters with constitutive or time-dependent high-expression activity by means of an EST-based approach in M. alpina 1S-4. Furthermore, the lengths of these promoter regions required to retain high expression levels were estimated by deletion analysis. The promoters data generated in this study will be beneficial for improvement in PUFA productivity and modification of PUFA composition, and may help elucidate the regulatory mechanisms of gene expression in M. alpina. 


\section{Acknowledgements}

This work was partially supported by the Program for Promotion of Basic and Applied

Researches for Innovations in Bio-oriented Industry (BRAIN) to J.O.; Advanced Low

Carbon Technology Research and Development Program (ALCA) to J.S.; Grants-in-Aid

for Scientific Researches (no. 22380051) from the Ministry of Education, Science,

Sports, and Culture of Japan to E.S.; and Institute for Fermentation, Osaka (IFO).

\section{References}

Ando A, Sakuradani E, Horinaka K, Ogawa J, Shimizu S (2009a) Transformation of an oleaginous zygomycete Mortierella alpina 1S-4 with the carboxin resistance gene conferred by mutation of the iron-sulfur subunit of succinate dehydrogenase. Curr Genet 55: 349-356.

Ando A, Sumida Y, Negoro H, Suroto DA, Ogawa J, Sakuradani E, Shimizu S (2009b) Establishment of Agrobacterium tumefaciens-mediated transformation of an oleaginous fungus, Mortierella alpina 1S-4, and its application for eicosapentaenoic acid producer breeding. Appl Environ Microbiol 75: 5529-5535.

Archer DB, Jeenes DJ, Mackenzie DA (1994) Strategies for improving heterologous protein production from filamentous fungi. Antonie Van Leeuwenhoek 65: 245-250.

Baneyx F (1999) Recombinant protein expression in Escherichia coli. Curr Opin Biotechnol 10: 411-421.

Beopoulos A, Nicaud JM, Gaillardin C (2011) An overview of lipid metabolism in yeasts and its impact on biotechnological processes. Appl Microbiol Biotechnol 90: 1193-1206.

Bradford MM (1976) A rapid and sensitive method for the quantitation of microgram quantities of protein utilizing the principle of protein dye binding. Anal Biochem 72: 248-254.

Cereghino JL, Cregg JM (2000) Heterologous protein expression in the methylotrophic yeast 
Pichia pastoris. FEMS Microbiol Rev 24: 45-66.

Courchesne NMD, Parisien A, Wang B, Lan CQ (2009) Enhancement of lipid production using biochemical, genetic and transcription factor engineering approaches. J Biotechnol 141: 31-41.

Gill I, Valivety R (1997) Polyunsaturated fatty acids, part 1: Occurrence, biological activities and applications. Trends Biotechnol 15: 401-409.

Hansson L, Blackberg L, Edlund M, Lundberg L, Stromqvist M, Hernell O (1993) Recombinant human milk bile salt-stimulated lipase. Catalytic activity is retained in the absence of glycosylation and the unique proline-rich repeats. J Biol Chem 268: 26692-26698.

Hata Y, Tsuchiya K, Kitamoto K, Gomi K, Kumagai C, Tamura G, Hara S (1991) Nucleotide sequence and expression of the glucoamylase-encoding gene ( $g l a A)$ from Aspergillus oryzae. Gene 108: 145-150.

Ichishima E, Taya N, Ikeguchi M, Chiba Y, Nakamura M, Kawabata C, Inoue T, Takahashi K, Minetoki T, Ozeki K, Kumagai C, Gomi K, Yoshida T, Nakajima T (1999) Molecular and enzymic properties of recombinant 1,2-a-mannosidase from Aspergillus saitoi overexpressed in Aspergillus oryzae cells. Biochem J 339: 589-597.

Jareonkitmongkol S, Kawashima H, Shirasaka N, Shimizu S, Yamada H (1992) Production of dihomo-Y-linolenic acid by a $\Delta 5$-desaturase-defective mutant of Mortierella alpina 1S-4. Appl Environ Microbiol 58: 2196-2200.

Jareonkitmongkol S, Shimizu S, Yamada H (1993) Production of an eicosapentaenoic acid-containing oil by a $\Delta 12$ desaturase-defective mutant of Mortierella alpina 1S-4. J Am Oil Chem Soc 70: 119-123.

Jefferson RA, Burgess SM, Hirsh D (1986) B-Glucuronidase from Escherichia coli as a gene-fusion marker. Proc Proc Natl Acad Sci 83: 8447-8451.

Jefferson RA, Kavanagh TA, Bevan MW (1987) GUS fusions: beta-glucuronidase as a sensitive and versatile gene fusion marker in higher plants. EMBO J 6: 3901-3907.

Kawashima H, Kamada N, Sakuradani E, Jareonkitmongkol S, Akimoto K, Shimizu S (1997) Production of 8,11,14,17-cis-eicosatetraenoic acid by $\Delta 5$ desaturase-defective mutants of an arachidonic acid-producing fungus, Mortierella alpina. J Am Oil Chem Soc 74: 455-459.

Kusakabe T, Koga K, Sugimoto Y (1994) Isolation and characterization of cDNA and genomic promoter region for a heat shock protein 30 from Aspergillus nidulans. Biochim Biophys Acta Gene Struct Expression 1219: 555-558.

MacKenzie DA, Jeenes DJ, Belshaw NJ, Archer DB (1993) Regulation of secreted protein production by filamentous fungi: Recent developments and perspectives. J Gen 
Microbiol 139: 2295-2307.

Mackenzie DA, Wongwathanarat P, Carter AT, Archer DB (2000) Isolation and use of a homologous histone $\mathrm{H} 4$ promoter and a ribosomal DNA region in a transformation vector for the oil-producing fungus Mortierella alpina. Appl Environ Microbiol 66: 4655-4661.

Makrides SC (1996) Strategies for achieving high-level expression of genes in Escherichia coli. Microbiol Rev 60: 512-538.

Minetoki T, Kumagai C, Gomi K, Kitamoto K, Takahashi K (1998) Improvement of promoter activity by the introduction of multiple copies of the conserved region III sequence, involved in the efficient expression of Aspergillus oryzae amylase-encoding genes. Appl Microbiol Biotechnol 50: 459-467.

Mumberg D, Muller R, Funk M (1994) Regulatable promoters of Saccharomyces cerevisiae: Comparison of transcriptional activity and their use for heterologous expression. Nucleic Acids Res 22: 5767-5768.

Ostergaard S, Olsson L, Nielsen J (2000) Metabolic engineering of Saccharomyces cerevisiae. Microbiol Mol Biol Rev 64: 34-50.

Punt PJ, Van Biezen N, Conesa A, Albers A, Mangnus J, Van Den Hondel C (2002) Filamentous fungi as cell factories for heterologous protein production. Trends Biotechnol 20: 200-206.

Raghukumar S (2008) Thraustochytrid marine protists: Production of PUFAs and other emerging technologies. Mar Biotechnol 10: 631-640.

Ranamalie Amarasinghe BHR, Faivre-Nitschke E, Wu Y, Udall JA, Dennis ES, Constable G, Llewellyn DJ (2006) Genomic approaches to the discovery of promoters for sustained expression in cotton (Gossypium hirsutum L.) under field conditions: Expression analysis in transgenic cotton and Arabidopsis of a Rubisco small subunit promoter identified using EST sequence analysis and cDNA microarrays. Plant Biotechnol J 23: 437-450.

Ratledge C (1993) Single cell oils - Have they a biotechnological future? Trends Biotechnol 11: 278-284.

Sakuradani E, Ando A, Shimizu S, Ogawa J (2013) Metabolic engineering for the production of polyunsaturated fatty acids by oleaginous fungus Mortierella alpina $1 \mathrm{~S}-4$. J Biosci Bioeng 116: 417-422.

Sakuradani E, Kobayashi M, Shimizu S (1999) $\Delta^{9}$-Fatty acid desaturase from arachidonic acid-producing fungus. Unique gene sequence and its heterologous expression in a fungus, Aspergillus. Eur J Biochem 260: 208-216.

Shen WJ, Forde BG (1989) Efficient transformation of Agrobacterium spp. by high voltage 
electroporation. Nucleic Acids Res 17: 8385.

Shimizu S, Ogawa J, Kataoka M, Kobayashi M (1997) Screening of novel microbial enzymes for the production of biologically and chemically useful compounds. Adv Biochem Eng 58: 45-87.

Sumi A, Okuyama K, Kobayashi K, Ohtani W, Ohmura T, Yokoyama K (1999) Purification of Recombinant Human Serum Albumin. Efficient purification using STREAMLINE. Bioseparation 8: 195-200.

Tada S, Gomi K, Kitamoto K, Takahashi K, Tamura G, Hara S (1991) Construction of a fusion gene comprising the Taka-amylase A promoter and the Escherichia coli B-glucuronidase gene and analysis of its expression in Aspergillus oryzae. Mol Gen Genet 229: 301-306.

Takeno S, Sakuradani E, Murata S, Inohara-Ochiai M, Kawashima H, Ashikari T, Shimizu S (2004a) Cloning and sequencing of the ura3 and ura5 genes, and isolation and characterization of uracil auxotrophs of the fungus Mortierella alpina 1S-4. Biosci, Biotechnol, Biochem 68: 277-285.

Takeno S, Sakuradani E, Murata S, Inohara-Ochiai M, Kawashima H, Ashikari T, Shimizu S (2004b) Establishment of an overall transformation system for an oil-producing filamentous fungus, Mortierella alpina 1S-4. Appl Microbiol Biotechnol 65: 419-425.

Takeno S, Sakuradani E, Tomi A, Inohara-Ochiai M, Kawashima H, Shimizu S (2005) Transformation of oil-producing fungus, Mortierella alpina 1S-4, using Zeocin, and application to arachidonic acid production. J Biosci Bioeng 100: 617-622.

Twyman RM, Stoger E, Schillberg S, Christou P, Fischer R (2003) Molecular farming in plants: Host systems and expression technology. Trends Biotechnol 21: 570-578.

Wurm FM (2004) Production of recombinant protein therapeutics in cultivated mammalian cells. Nat Biotechnol 22: 1393-1398. 
Table 1. Information regarding genes for selected promoters

\begin{tabular}{|c|c|c|}
\hline Gene & Annotation & t abundance ${ }^{a}$ \\
\hline PP1 & Predicted protein & 35.7 \\
\hline PP2 & Predicted protein & 29.0 \\
\hline PP3 & Predicted protein & 11.7 \\
\hline SSA2 & ATP binding protein (member of HSP70 family) & 8.9 \\
\hline PP7 & Predicted protein & 7.9 \\
\hline SSA22 & ATP binding protein (member of HSP70 family) & 7.6 \\
\hline PP4 & Predicted protein & 7.3 \\
\hline PP8 & Predicted protein & 6.6 \\
\hline SAH1 & $S$-Adenosyl-L-homocysteine hydrolase & 6.6 \\
\hline PET9 & $\mathrm{ADP} / \mathrm{ATP}$ carrier of the mitochondrial inner membrane & 6.0 \\
\hline HSP104 & Hsp that cooperates with Hsp40 and Hsp70 & 5.9 \\
\hline HSC 82 & Cytoplasmic chaperone of the Hsp90 family & 5.6 \\
\hline UBC5 & Ubiquitin-conjugating enzyme & 4.7 \\
\hline CDA1 & Chitin deacetylase & 4.5 \\
\hline RPP0 & Ribosomal protein $\mathrm{P} 0$ & 4.0 \\
\hline PP5 & Predicted protein & 4.0 \\
\hline PP6 & Predicted protein & 3.8 \\
\hline RPS16B & Protein component of $40 \mathrm{~S}$ ribosormal subunit & 3.2 \\
\hline EFB1 & Translation elongation factor 1 beta & 2.6 \\
\hline TDH1 & Glyceraldehyde-3-phosphate dehydrogenase & 2.4 \\
\hline CIT1 & Citrate synthase & 2.0 \\
\hline TIF2 & Translation initiation factor eIF4A & 1.9 \\
\hline CAT2 & Carnitine acyl-CoA transferase & 0.9 \\
\hline ELO1 & Fatty acid elongase I & 0.7 \\
\hline IPP1 & Cytoplasmic inorganic pyrophosphatase & 0.7 \\
\hline OLE1 & Delta-9 fatty acid desaturase & 0.6 \\
\hline PGK1 & 3-Phosphoglycerate kinase & 0.4 \\
\hline
\end{tabular}

${ }^{a}$ EST abundance data show the total for EST transcriptional abundance at different cultivation stages, by using relative values for histone H4.1. For cultivation conditions, see materials and methods. 


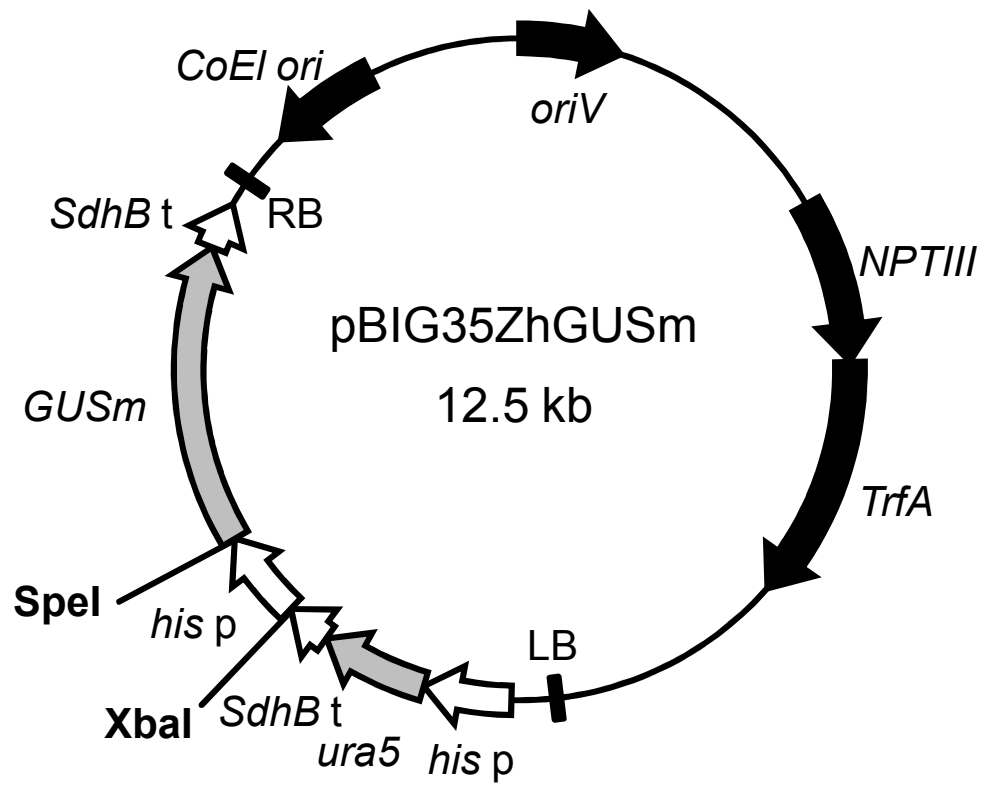

Fig. 1. Vector construct used in M. alpina 1S-4 promoter assays. GUSm, codonoptimized $\beta$-glucuronidase gene for $M$. alpina; his $\mathrm{p}, M$. alpina histone H4.1 promoter short fragment; $S d h B$ t, $M$. alpina $\mathrm{SdhB}$ transcription terminator; ura5, orotate phosphoribosyl transferase gene of M. alpina $1 \mathrm{~S}-4$; NPTIII, neomycin phosphotransferase III gene; TrfA, TrfA locus, which produces 2 proteins that promote replication of the plasmid; ColEI ori, ColEI origin of replication; oriV, pRK2 origin of replication; RB, right border; LB, left border.

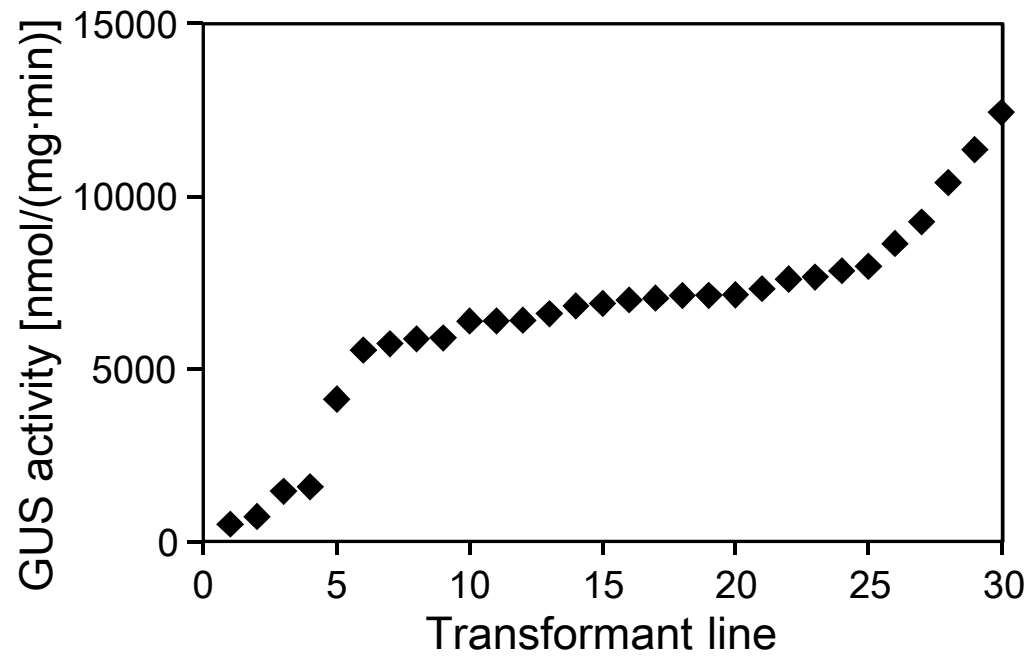

Fig. 2. Distribution of GUS activity levels driven by the $H S C 82$ promoter in $M$. alpina transformants cultivated for $5 \mathrm{~d}$ in GY liquid medium. Each plot denotes individual transformants, and all plots are sorted in ascending order of GUS activity. GUS activity is expressed in nanomoles of $p$-nitrophenol produced per minute per milligram of protein. 


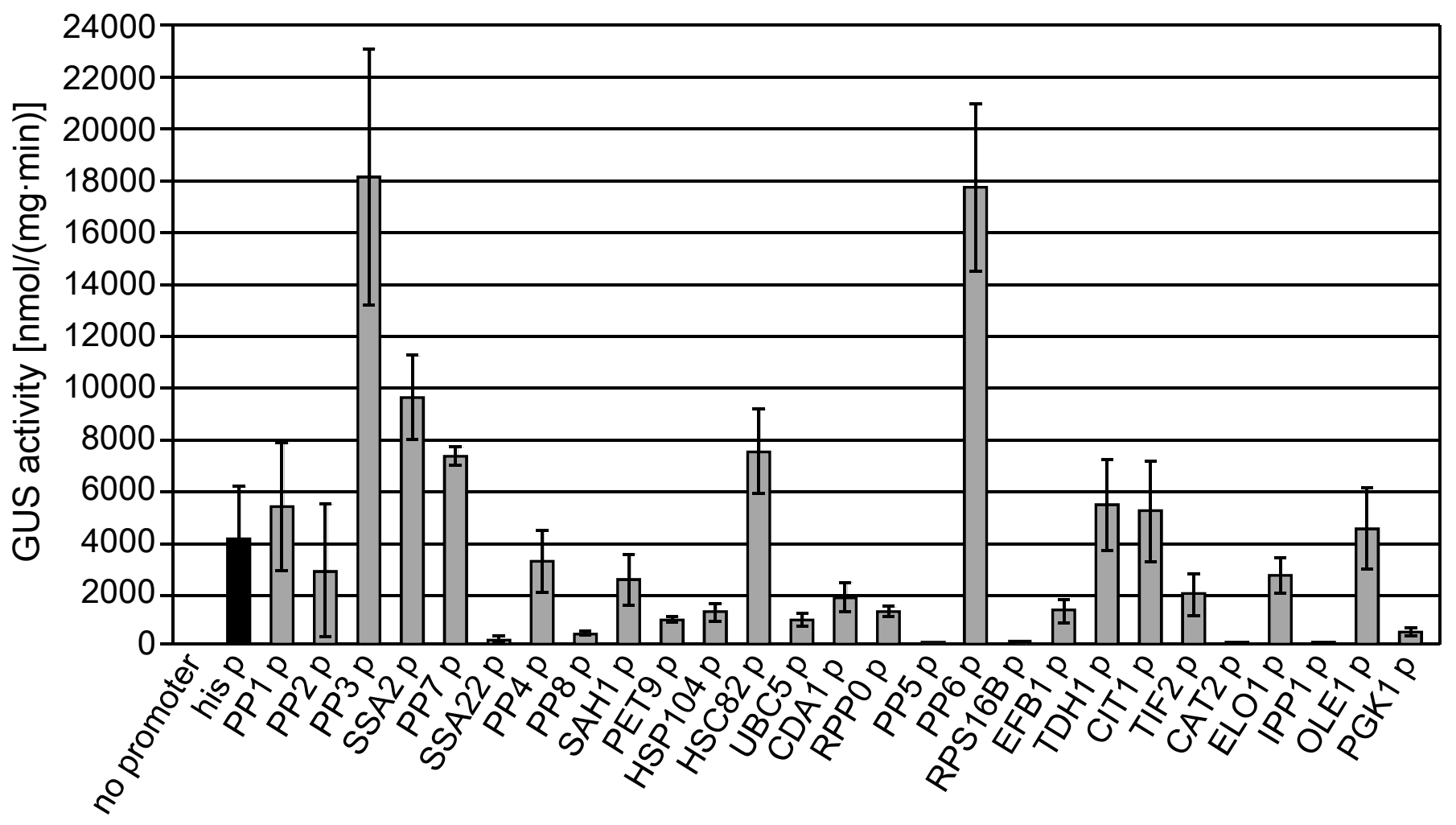

Fig. 3. GUS activity driven by various promoters in $M$. alpina transformants cultivated for $\mathbf{5} \mathbf{d}$ in GY liquid medium. GUS activity is expressed in nanomoles of $p$ nitrophenol produced per minute per milligram of protein. The Bars represent the mean values with standard deviations of GUS activity in 10 individual transformant lines for each promoter construct. 

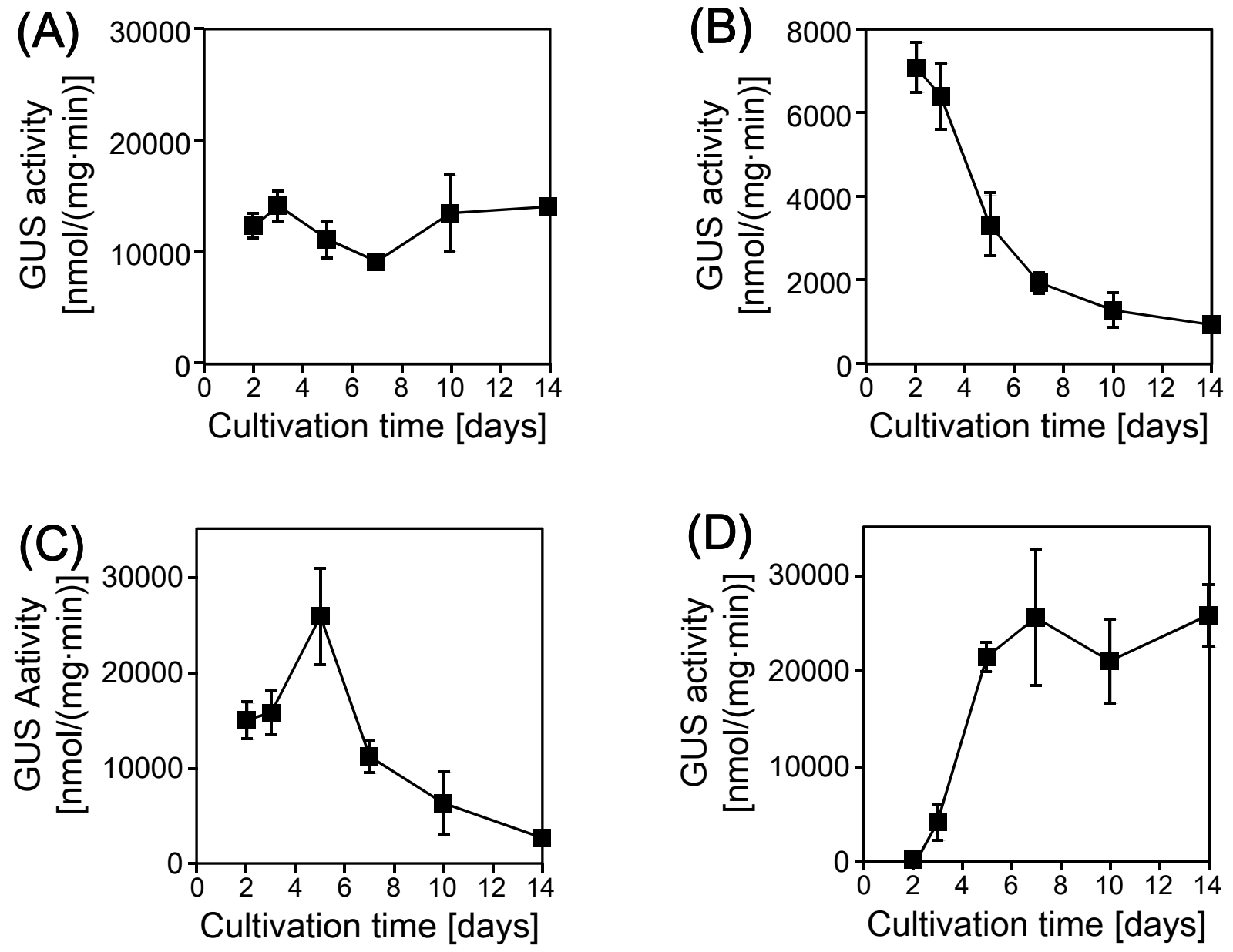

Fig. 4. Representative patterns of time-depend changes in GUS activity with different promoters. Results with (A) HSC82, (B) CIT1, (C) PP6 and (D) PP3 promoters are shown as representative. All transformants for each promoter construct were cultivated in GY medium for 2-14 d. GUS activity is expressed in nanomoles of $p$ nitrophenol produced per minute per milligram of protein. Plots represent the mean values with standard deviations of GUS activity in 3 individual transformant lines for each construct. 


\section{PP2p}

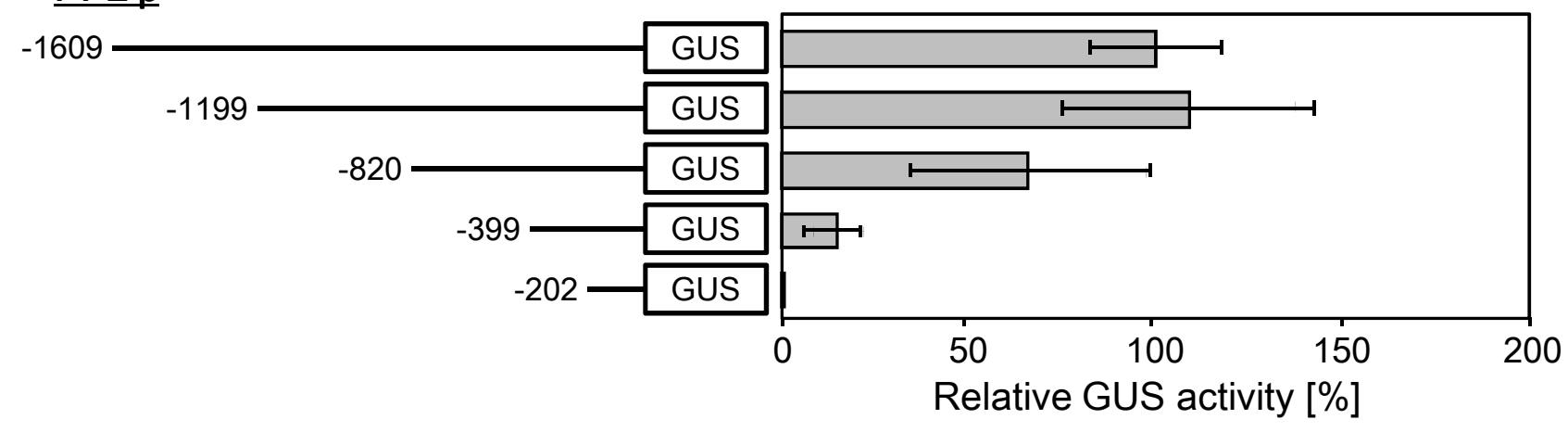

\section{PP3p}

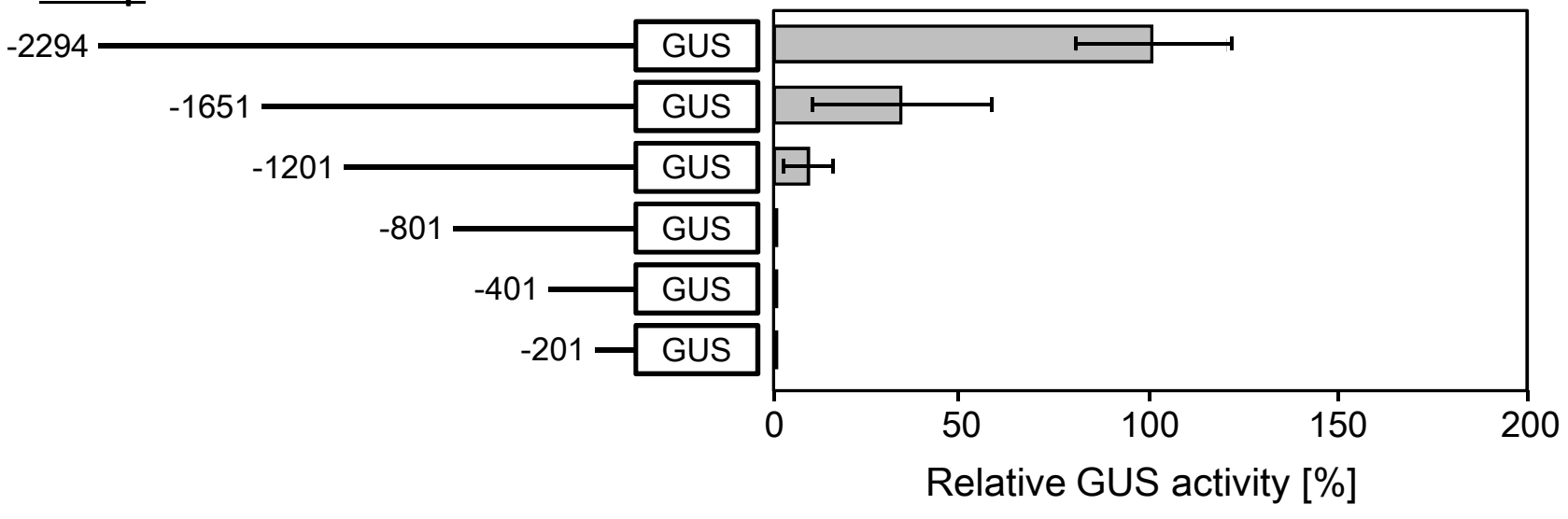

\section{SSA2p}

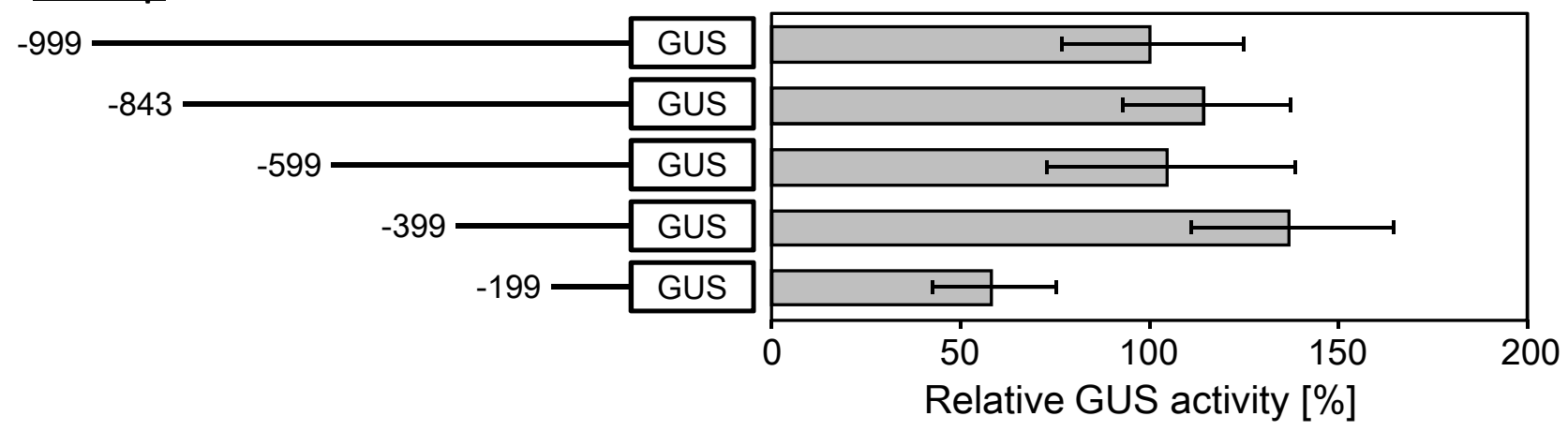

\section{PP7p}

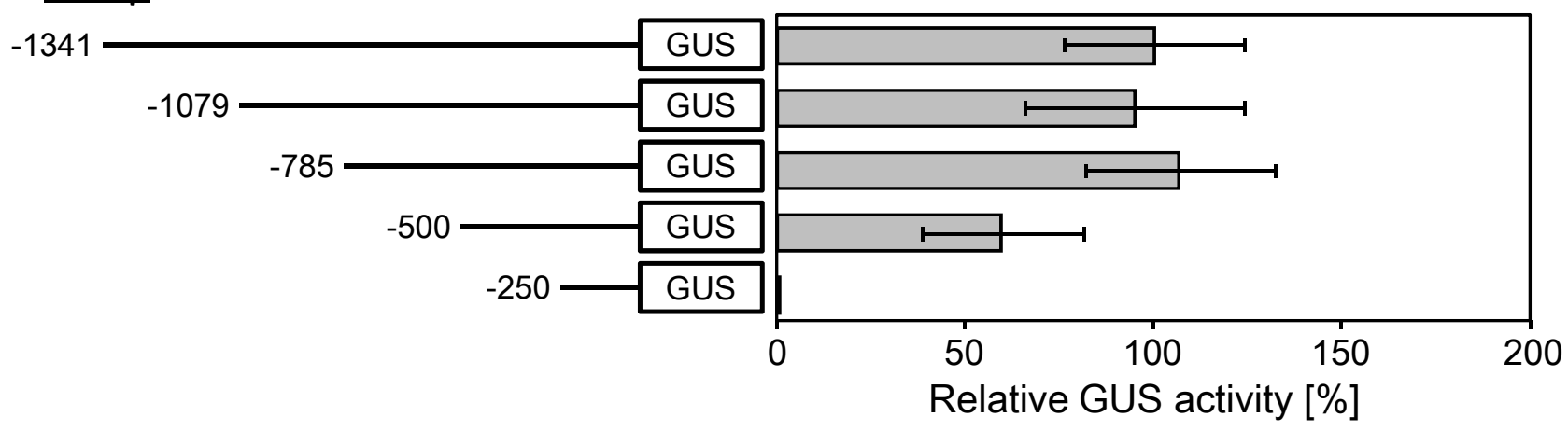




\section{HSC82p}
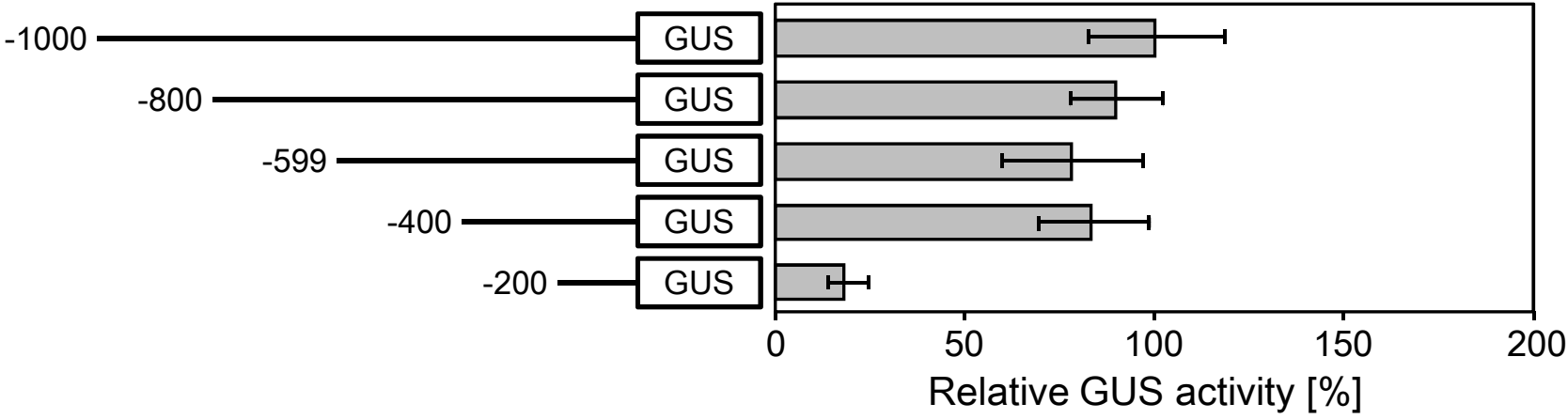

PP6p

$-1519$
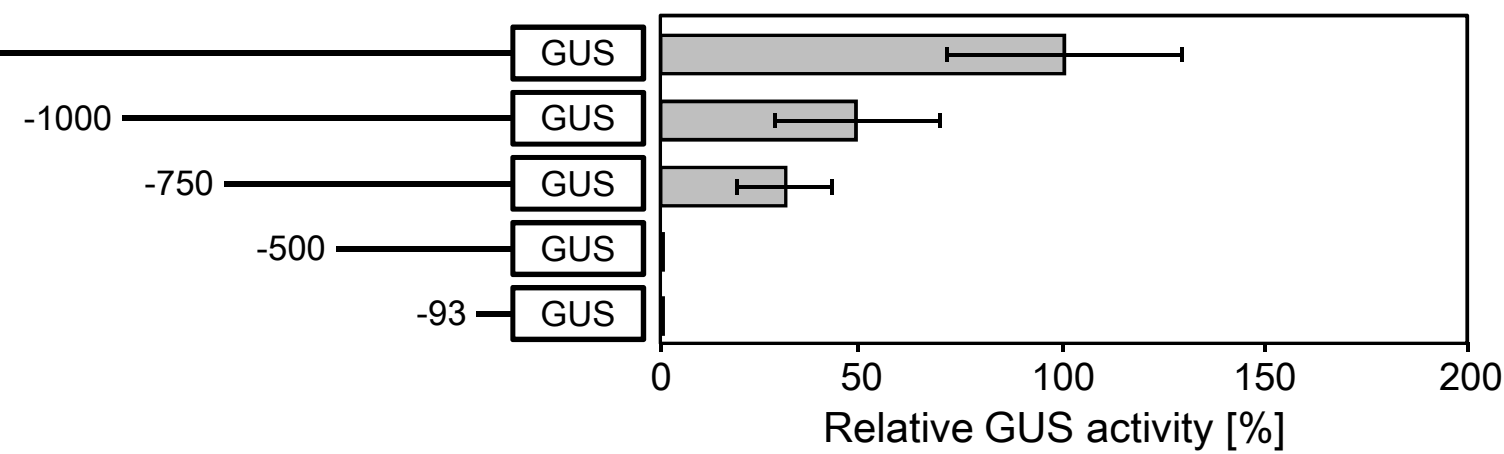

$\underline{\text { CIT1p }}$
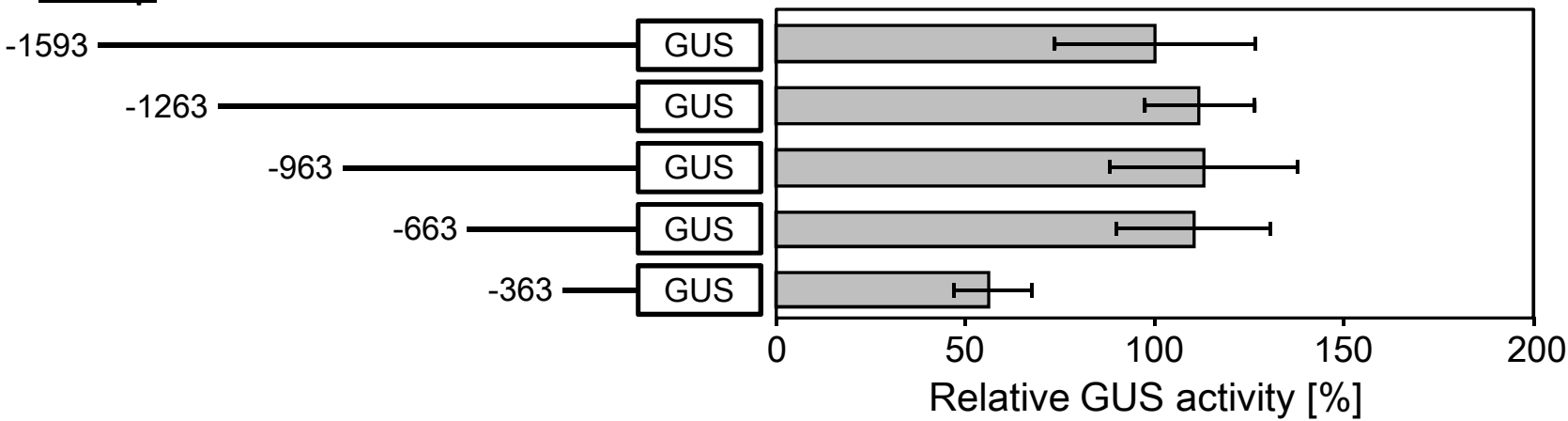

Fig. 5. 5'-deletion analysis of 7 different promoters. In the left column, constructs with different $5^{\prime}$ upstream deletions of individual promoters are shown. For each construct, the length of the fragment upstream from the transcription start site is shown on the left end. Putative PolII transcription factor binding sites are indicated by closed triangles. In the right column, GUS activity levels with the deleted constructs in M. alpina transformants are shown. All transformants were cultivated in GY liquid medium. Cultivation times were $5 \mathrm{~d}$ for the SSA2, HSC82, PP7 and PP6 promoters, $3 \mathrm{~d}$ for the CIT1 promoter, and $14 \mathrm{~d}$ for the $P P 2$ and $P P 3$ promoters. The average GUS activity of each full-length construct is set at $100 \%$ and has been used to define the relative GUS activity of individual deletion constructs. Bars represent the mean values with standard deviations of GUS activity in 10 individual transformant lines for each construct. 
Table S1. PCR primers for selected promoters

\begin{tabular}{|c|c|c|}
\hline Promoter & Primer F sequence $\left(5^{\prime}-3^{\prime}\right)$ & Primer R sequence $\left(5^{\prime}-3^{\prime}\right)$ \\
\hline PP1 p & AATCTCTAGA $^{\text {a GCGCAGTCGGAATGCC }}$ & AGTAACTAGTCGTGTTTTCTTTTGAAATGGG \\
\hline $\mathrm{PP} 2 \mathrm{p}$ & AAGCTCTAGAGACTGTAAAGACGGAGGGG & AGTAACTAGTTGTGGATAGTGGGTAGTGG \\
\hline PP3 $p$ & AACGTCTAGACGTGTTATCTTGCGCTGC & TCAT $\underline{\text { ACTAGTGATGATTTAGAGGTGTTGG }}$ \\
\hline SSA2 p & TTAGTCTAGAAAAGTGCTGCTTCGGAACC & AGATACTAGTGATGTAGATGTGAGTGTGAG \\
\hline PP7 $p$ & AATATCTAGATGACCGTGCGCTTTTTGAGAC & AGCAACTAGTCGTATATTTGTTGAAAGGTG \\
\hline SSA22 $p$ & AATATCTAGAGGGTGCAGGTCCGGTCC & 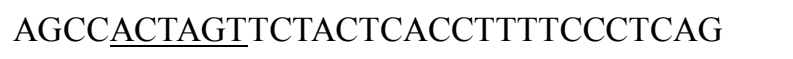 \\
\hline PP4 p & TGAGTCTAGAAGAGTGATTTTGTGGCTGTAC & CAATACTAGTGGCTGATGTATGTGTTGATG \\
\hline PP8 $\mathrm{p}$ & ATGCTCTAGATATGGCGACCCATTCACG & 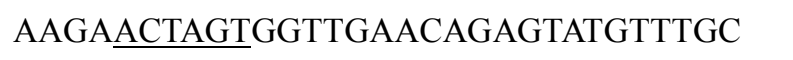 \\
\hline SAH1 $\mathrm{p}$ & AATCTCTAGACTGGCGAATACATGCGCAC & ATAGTCTAGAGGTGGATATGAAGGGTGG \\
\hline PET9 $p$ & ACCTTCTAGAAGACGAGAAGAGTTCATGATG & AATAACTAGTGATGAGTGTATGTGGAGAGTG \\
\hline HSP104 p & AATATCTAGAGTTGAAGGTGCAGACACCGG & AATAACTAGTGGTGGGGCGTTATGTGG \\
\hline $\mathrm{HSC} 82 \mathrm{p}$ & ATCATCTAGAGAGCTCAAGATGAAGGTGCTC & AATAACTAGTGGTGTGTGTGGTTTGCGGG \\
\hline UBC5 $\mathrm{p}$ & AACTACTAGTGTATACAGGTCTTAGAGACC & ATTCACTAGTCGTGGGTGGAGAGAGTG \\
\hline CDA1 $\mathrm{p}$ & AACTCTAGATGAAAATAGAAATGGGTGGATGG & ATTGACTAGTCGTAGGTTTCTTTGTGTGTG \\
\hline RPP0 $p$ & AATGTCTAGACACAGTGACAAGGGTGTTAAC & ATGCACTAGTGTTGATTATTGTTCGAGGG \\
\hline PP5 $\mathrm{p}$ & AACGTCTAGATGTTTTTTGTGCAAATTACCTCG & AAGCACTAGTTTTGGATTGGGATTGCTTGAG \\
\hline PP6 p & AAAGTCTAGACTGGCAATAGTTAGTGCACG & ATCAACTAGTGATGGAGGTTTGTTTGAGAAG \\
\hline RPS16B p & AATGTCTAGACCTGCAGAAAGATGATCCAAAAG & AAGCACTAGTGATGAATAATGCCTATGATCAG \\
\hline EFB1 $p$ & TTAGACTAGTCGTAGTTGACTCTTTTATG & CAGTACTAGTGGTGGGTGCTTTGTCGATTTG \\
\hline TDH1 p & AACCTCTAGAAGGAAATAAATTCTCCTCGGTG & 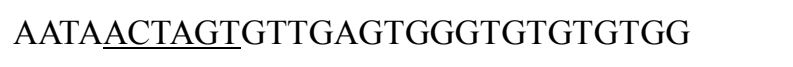 \\
\hline CIT1 p & ATTTTCTAGACACCTCAAAAACGTGCCTTG & 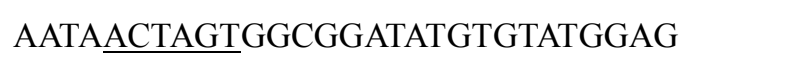 \\
\hline TIF2 $\mathrm{p}$ & AAGTTCTAGAGTCGACCTATCATCATTTTTGGC & AGCGACTAGTGTTTTTTTTTGCTTTTTTTTTTATG \\
\hline CAT2 p & AATCACTAGTAAACGGTGGAGCATTCTCAC & TATCACTAGTGAAGGCGATGGGCAGGG \\
\hline ELO1 $\mathrm{p}$ & AATGTCTAGACTTGCCCAGCATTACTCC & TCATACTAGTCTTTGAGGGGAGGAATTGC \\
\hline IPP1 $\mathrm{p}$ & ACAATCTAGAGGCTGCGTTGCCGGGAG & ATAGACTAGTGGTGGTGGTGAAGAGTAG \\
\hline OLE1 $\mathrm{p}$ & AGCATCTAGAGGGTTCTCACATTGAATTTG & AATAACTAGTCGCTGTGCGTCCTGCGTTG \\
\hline PGK1 p & TGAATCTAGACACCGTCGCTATGTGAAG & TTGCTCTAGAGCAGAAACACACTGGCAG \\
\hline
\end{tabular}

\footnotetext{
${ }^{\mathrm{a}}$ The underlined sequences show synthesized $\mathrm{Xba \textrm {I }}$ (TCTAGA) and SpeI (ACTAGT) sites.
} 
Table S2. PCR primers used for deletion clones

\begin{tabular}{|c|c|c|}
\hline Promoter & Length of deletion clone (bp) & Primer F sequence $\left(5^{\prime}-3^{\prime}\right)$ \\
\hline \multirow[t]{4}{*}{ PP2 $\mathrm{p}$} & 1199 & ATTTCTAGA $^{\mathrm{a} T G C A T T T A C A G G T G A A T A T T A C}$ \\
\hline & 820 & TTATCTAGACATAAAAGTGTCTGGAGCG \\
\hline & 399 & TTATCTAGAACTAAGTGGTGTCTACTTTGG \\
\hline & 202 & AATTCTAGAGGATACTCCATCCCCACCC \\
\hline \multirow[t]{5}{*}{ PP3 p } & 1651 & AATATCTAGAGATCCTGGTCGAAAAAGACAG \\
\hline & 1201 & AATGTCTAGATGAGTTTCTGTTTTTTCCTTTTTGC \\
\hline & 801 & AATATCTAGATGAACAATTCATGCAGCTTCACG \\
\hline & 401 & AATATCTAGACGTCTAAGCGTTTACGTGCC \\
\hline & 201 & AATATCTAGACTCGTTTTGATGGAGTTCTC \\
\hline \multirow[t]{4}{*}{$\mathrm{SSA} 2 \mathrm{p}$} & 843 & AGTATCTAGATGACGGCGTGTATATGTCAG \\
\hline & 599 & AGGTTCTAGACCATTGTATCGATTTCTGAT \\
\hline & 399 & AGTATCTAGAGCTATGCGAACGGTTCATTTTG \\
\hline & 199 & AGGTTCTAGATTTTTTCTCTCTGGTGTGAACG \\
\hline \multirow[t]{4}{*}{ PP7 p } & 1079 & AGCATCTAGAAAAACTATTCAATAATGGGCG \\
\hline & 785 & ATTTCTAGAATGGCGAGACGCAGGGGGTAG \\
\hline & 500 & AATATCTAGAGAGTGGGCACTGAACTAAAAAG \\
\hline & 250 & AATATCTAGAGACACTGCATGACGCGAAATC \\
\hline \multirow[t]{4}{*}{$\mathrm{HSC} 82 \mathrm{p}$} & 800 & AATTCTAGATTTTACTACCGCATTCCCTTTTC \\
\hline & 599 & ACGTCTAGACCTTTTCAGTAAACAATTTC \\
\hline & 400 & ATTTCTAGACACAAAGAAGAAGGGTGTGTC \\
\hline & 200 & ACGTCTAGAACTGTTTTCTTGAAACTTC \\
\hline \multirow[t]{4}{*}{ PP6 $\mathrm{p}$} & 1000 & AATTCTAGACAGTTACCGTGCGCCCACTG \\
\hline & 750 & AATTCTAGACTTTCACAAATAGGCATCCTATC \\
\hline & 500 & AATTCTAGAGGCTTTTTCGTTTATTGGATTG \\
\hline & 93 & ACGTCTAGATATCCAATTCTCACCACTTC \\
\hline \multirow[t]{4}{*}{ CIT1 p } & 1263 & AAGTCTAGATGTCAATCATCTTTGCTGCTG \\
\hline & 963 & TGCGTCTAGAATTATAATTATAATGAGGAAGTG \\
\hline & 663 & TTATCTAGAGGCGAGTGGCGGACTGC \\
\hline & 363 & TTGTCTAGACAATTGGCAAGGCTGGGTTG \\
\hline
\end{tabular}

${ }^{a}$ The underlined sequences show synthesized $X b a \mathrm{I}$ (TCTAGA) site. 